DOI 10.37882/2500-3682.2021.05.21

\title{
МУЗЫКАЛЬНАЯ ТРАДИЦИЯ СИРИЙСКОЙ ПРАВОСЛАВНОЙ ЦЕРКВИ И ЕЕ ВЛИЯНИЕ НА СОВРЕМЕННУЮ СИРИЙСКУЮ МУЗЫКУ
}

\section{THE MUSICAL TRADITION OF THE SYRIAN ORTHODOX CHURCH AND ITS INFLUENCE ON MODERN SYRIAN MUSIC}

\section{Maksoud Marilyn}

Summary: The musical tradition of the Syrian Orthodox Church has repeatedly attracted the attention of art critics and cultural experts. The origin of the Syrian Orthodox church music culture can be traced back to the dawn of Christianity. The results of this study will allow us to point out the reasons due to which the Syrian church music has unique features, making it a special phenomenon in the musical culture of the Orthodox world. These factors are considered in the article as an attempt to supplement and expand the already existing body of knowledge about the musical tradition of the Syrian Orthodox Church and its influence on contemporary Syrian music.

Keywords: Syrian Orthodox Church, musical tradition, contemporary Syrian music, Middle East, religious Christian compositions.

\author{
Максуд Марлен \\ Аспирант, Санкт-Петербургский государственный \\ университет \\ marilyn.maksoud@gmail.com
}

Аннотация: Музыкальная традиция Сирийской православной церкви неоднократно привлекала внимание искусствоведов и культурологов. Зарождение сирийской православной церковной музыкальной культуры можно проследить еще на заре христианства. Результаты данного исследования позволят указать причины, благодаря которым Сирийская церковная музыка обладает уникальными чертами, сделав её особым явлением в музыкальной культуре православного мира. Обозначенные факторы рассматриваются в статье, как попытка дополнить и расширить уже существующий массив знаний о музыкальной традиции Сирийской православной церкви и ее влиянии на современную сирийскую музыку.

Ключевые слова: Сирийская православная церковь, музыкальная традиция, современная сирийская музыка, Ближний Восток, религиозные христианские композиции.
$\mathrm{M}$ узыкальная традиция Сирийской православной церкви берет свое начало в первых христианских общинах Ближнего Востока и вплоть до настоящего времени сохраняет свой собственный стиль и уникальность. К сожалению, изучение формирования и становления сирийской музыкальной традиции еще довольно слабо изучено и является одним из белых пятен культурологической науки. В данной статье осуществляется попытка обозначить основные этапы формирования музыкальной культуры сирийской церкви, а также то влияние, которое она оказала на музыкальную культуру Сирии в целом.

Известно, что музыка и песнопения были важной составляющей христианства с первых веков его существования. Еще апостол Павел, основавший Антиохийскую общину, говорил: «Назидая самих себя псалмами и славословиями, и песнопениями духовными, поя и воспевая в сердцах ваших Господу» [7, с. 307]. Являясь авраамической религией, христианство испытывало на себе ощутимое влияние иудаизма. Как известно, в данной традиции псалмы, гимны и музыкальные инструменты были органическим компонентом религиозных ритуалов, что также было перенято христианами для богослужений.

Но музыкальная традиция Сирийской православной церкви в процессе своего развития опиралась не только на песнопения первых христиан и наследие иудаизма. Определение её генезиса и фундаментальных источников в процессе формирования представляет собой основной предмет настоящего исследования.

«Музыкальной традиции Сирии с момента её зарождения была присуща устная форма передачи, открытость и отсутствие жесткой структурированности, что способствовало её широкому распространению среди различных слоев населения» [2, с. 95]. Эти факторы также можно считать причинами того, что на неё оказывали существенное влияние культуры и традиции соседних стран, но несмотря на это, ключевые аспекты становления данной музыкальной традиции исторически связаны именно Сирией.

Первые религиозные христианские композиции опирались как на фольклорную традицию, так и на предшествовавшие им обрядовые языческие песнопения, видоизмененные для нужд нового вероучения. Среди авторов, осуществивших этот труд можно отметить: Маравама, Марабола, Якоба Саруджи, Шимона Аль-Фахари.

«Христианизация территории Сирии проходила довольно медленно, особенно это касается областей, на- 
ходившихся за пределами непосредственного влияния Антиохийской церкви» [6, с. 17]. Но и после утверждения нового вероучения на территории данного региона, его население продолжало позиционировать собственную идентичность в сфере религиозной жизни. Иерархи Сирийской Православной церкви не приняли положения Халкидонского собора 451 года, что привело к её обособлению от Византийской церкви и созданию собственных патриарших кафедр.

Постепенно Сирийская православная Церковь все более впитывала и интегрировала в свою музыкальную традицию более простые и близкие народу фольклорные стили. Среди наиболее известных подвижников Сирийского Православия, оказавших влияние на его музыкальную традицию, можно отметить Иоанна Дамаскина, написавшего песнопения (гимны) - так называемые «каноны», состоящие из девяти связанных друг с другом од. Каждая песнь данного канона включает в себя вводный тропарь и еще несколько тропарей с разным текстом, исполняемые в одинаковом с ведущей мелодией ритме. Св. Иоанн Дамаскин обозначил характерные именно для сирийской церковной одноголосой музыки особенности, уделив много внимания её развитию.

Значительная роль в исследовании влияния церковной музыкальной традиции на сирийскую культуру принадлежит Нури Искандару. В одном из своих интервью он говорит о том, что десять лет прожил в городе Алеппо, посещая мечеть, где слушал зикры и мавлиды. Он пришел к выводу, что исламские ритуальные мелодии являются прямым продолжением сирийской музыки и закономерным этапом её развития.

Будучи христианином Нури Искандар на протяжении многих лет изучал церковную музыкальную традицию и её взаимодействие с народной сирийской музыкой. Так, например, он выяснил, что аль-Кудуд аль-Халабия (одно из аутентичных сирийских музыкальных искусств, которым город Алеппо славился с древних времен) в некоторых своих аспектах является интерпретацией церковных мелодий, на которые были положены слова народных песен.

Наглядным примером прямого заимствования народом церковной мелодии является гимн «Тарао Дилох Хануну», который можно перевести с арамейского как «Врата Господни есть добро». В фольклорной традиции он превратился в песню «Аль-Бюльбюль Наги Госн АльФуль», что значит «Бюльбюль сидит на ветке и поет».

Кроме того, сам Нури Искандар в своем творчестве опирался на музыкальную традицию сирийской православной церкви. Из наиболее значимых его трудов следует отметить «Ахаат», «Неми Омран», «Концерт для уда», «Диалог любви», «Концерты для лютни и виолончели» и
«Трехсоставная струна». Среди них можно выделить целый ряд поэм, объединенных общей темой. Например, поэма «Хатама» принадлежащая перу Хуссейна Хамзи, которая еще не была выпущена на CD, но при этом, неоднократно исполнялась, в том числе в Швеции в 1989. На арамейском её название звучит как «Баркана» - что означает «наслаждаться».

Мунир Вахиба аль-Хазен акцентировал внимание на том, что историки расходятся во мнениях относительно даты появления сирийской музыки в восточных церквях. Но вполне вероятно, что первым, кто использовал мелодии и песни был Вафа - сирийский философ, который жил до нашей эры. Христианская революция была основана на всех проявлениях роскоши, экстравагантности и погружении в объятия удовольствий, которые были распространены в римскую эпоху. Но эта ситуация многое перевернула с ног на голову, и первые христиане начали считать музыку нарушением религии. В связи с этим обстоятельством она была запрещена в периоде ранней церкви. Уточнялось, что музыка является инструментом для пробуждения инстинктов, поэтому верующим достаточно было религиозной медитации, благоговения, молитвы и аскезы.

По мнению Нури Искандара, в первые три века христианства верующие использовали мелодии еврейской синагоги из-за отсутствия христианских мелодий. Поэтому псалмы Давида, книга песнопений, притчи, причитания Иеремии, ученики Исайи и хвала трех мальчиков в печи - все эти молитвы с их мелодиями вошли в церковное служение. В итоге отцы сирийской церкви добавили тексты, псалмы и гимны в ход литургии, которая не была завершена до конца седьмого века святым Иаковом арРахави (209 г.). Результатом этого обстоятельства стало появление следующих сирийских мелодий:

1. Языческие мелодии, предшествовавшие христианской эпохе, на которые были установлены новые религиозные тексты с христианскими концепциями.

2. Мелодии, составлены и сочинены отцами церкви, такими как: Мар Эфрем, Мар Рабула 435 г. н.э., Якуб аль-Суруджи 521 г. н.э., Шимон аль-Фахар 514 г. н.э., Мар Суириус Антиохийский 538 г. н.э., Мар Исхак, Мар Палай, Мар Я куб аль-Рахави 708 г. н.э.

В конце IV века значительную роль в деле развития православной духовной музыки Сирии сыграл Мар Афрем аль-Сириани, особой заслугой которого явилось привлечение для церковных песнопений женского хора. В целом для музыкальной культуры сирийского Православия голос исполнителя всегда являлся значимым элементом.

Согласимся с мнением Нури Искандара, что сирийская церковная музыка является продолжением древ- 
ней языческой музыкальной традиции Сирии и Месопотамии. По его мнению, в период язычества храмовой музыке был присущ гораздо больший драматизм, чем в христианскую эпоху. В недрах церковной музыкальной традиции он прослеживается крайне редко, в особых случаях. Например, в особой службе на страстную пятницу, чтобы подчеркнуть трагизм мученической смерти Христа.

Важным остается и тот факт, что «музыка не вошла бы в сирийскую церковь быстро, легко и спонтанно, если бы песнопения и гимны не исполнялись на родном языке. Якуб аль-Бартали, в XIII веке писал, что христиане пели свои псалмы не только в церквях, но также и в домах, на площадях и дорогах» [3, с. 197]. Также он свидетельствует, что они при этом использовали гонги, гитары, бубны, тарелки и трубы.

Из вышесказанного становится ясно, что музыка вошла в богослужение в сирийской церкви если не с момента ее зарождения в первом веке нашей эры, то, по крайней мере, во времена святого Афрама Аль-Сирианеа в IV веке. Это очень важный факт для исследования подлинности сирийской церковной музыки. Если бы эта музыка не была частью культурной традиции сирийского народа, она не вошла бы с такой легкостью и спонтанностью в церковь Сирии и не смогла бы выразить самые сокровенные тайны его духовной жизни.

Сирийская музыкальная традиция состояла из восьми ладов, так называемых Икадис в соответствии с книгой Аль-Лу'лу'аль-Мантур («Рассеянный жемчуг») патриарха Афрама Бурсума I [2]. Она зародилась в Греции и была распространена в древности на довольно широкой территории - Сирии, Ираке, Индии, части Азии и Турции. Данная музыкальная традиция сохраняется в недрах Сирийской православной церкви и народной музыки вплоть до настоящего времени.

Изначально в сирийской музыке было двенадцать основных ладов. Четыре из них не соответствовали традициям литургического богослужения, поэтому церковники отказались от них, оставив лишь восемь. Нури Искандар дает научное описание каждого из этих ладов, связывая их с определенным музыкальным жанром каждого из родов, населявших территорию Ближнего Востока. «Первый и второй лады он связывает с родом баят, третий с родом сика, четвертый с родом раст, пятый с родом хиджас, используемый в сельской местности вышеупомянутого региона и с родом раст, который распространен сейчас в Турции. Шестой восходит к роду нахаванд, а седьмой - к роду саба. Последний, восьмой лад он отчасти связывает с родом раст» [9].

Восьмиладовая традиция существовала повсеместно вплоть до VII века, когда данную территорию завоевали арабы, которые использовали её для создания своей собственной музыкальной традиции - так называемых макамов. Таким образом, можно утверждать, что макамы являются прямым продолжением сирийской музыкальной традиции, представляя следующий этап её развития с увеличением художественных формул. Сирийская национальная и церковная музыка свое начало взяла от арабской музыкальной традиции.

Кроме того, на музыку сирийского православия оказала значительное влияние музыкальная традиция местного населения данного региона. «После обособления от влияния Византии, сирийская церковь шла на все большее сближение с местной традицией, впитывая в себя её черты и особенности» [7, с. 46]. Церковные песнопения и гимны слагались на основании народных мотивов, близких и понятных большинству населения. Благодаря этому фактору церковная музыка не воспринималась населением как нечто чуждое и далекое, а становилась частью народной культуры, что позволило в будущем произойти обратному процессу, - когда церковные гимны и песнопения превращались в популярные светские песни.

Известно, что сирийцы были народом, приверженным к поклонению, и всегда исполняли религиозные обязанности касательно духовных гимнов и песнопений. С приходом христианства и присоединением язычников к этой новой религии группами, появилось много языческих мелодий, которые пели в храмах, и которые вошли в сирийские христианские церкви, став частью их мелодий. Они были собраны и добавлены уже нашими сирийскими предками в книге «Бейт Каз». Это название книги означает «Хранилище мелодий». Сирийская церковь унаследовала эти древние мелодии и действительно стала их надежным хранилищем.

По этому поводу Патриарх Ефрем I Барсум (18871957) говорит в своей книге «Аль-Лу'лу 'Аль-Мантур»: «Священники согласились с этим, то есть введя языческие мелодии по трем причинам: противостоять язычеству и тем, кто принял ересь, и кто пытался развратить молодежь, их веру и нравственность [2, с. 54]. Использовали эти мелодии в богослужении, чтобы отвести скуку от поклоняющихся, читая длинные гимны и пробуждать чувства к осознанию смысла молитвы, потому что, если поклоняющиеся поют или слышат пение они впитывают значение того, что они поют и так быстрее молитва проникает в их души и глубже в их сердца и вызывает благоговение. Священники следовали этому методу подобному пророку Давиду и его организованному хору.

Последователи сирийской церкви в Иерусалиме - евреи и эдомитяне в эпоху римской империи и с приходом в новую религию начали использовать церковные гимны на арамейском языке, взятые из книг Торы и Псалтири Давида. 
«Псалмы - это сирийский феномен, означающий песни, и их количество составляет 150 псалмов, каждый псалом имеет название, указывающее на его происхождение или на его тип, или на музыкальные инструменты, сопровождающие его, или указывающее на его мелодию и использование в богослужении» [8, с. 250] В связи с этим сирийский музыкант Нури Искандар пишет: «Первая христианская церковь в Иерусалиме и вторая в Антиохии были сначала под влиянием некоторых еврейских в гимнах, таких как Псалмы» [4]. Но это не означает, что музыка первой христианской церкви (Сирийской) основана в целом на иврите, и нет сомнений в том, что евреи заимствовали свою музыку из Месопотамии и они заимствовали шумерскую музыкальную гамму из поколения в поколение и использовали ее во времена Ездры [5].

Музыкальная традиция Сирийской Православной церкви опиралась в своем становлении на четыре основных фактора:

1. видоизмененные для нужд церкви обрядовые языческие песнопения культов, существовавших на данной территории в дохристианский период;

2. фольклорная музыка народов Сирии, Ассирии и Армении, которая была интегрирована в церковную музыкальную традицию;

3. музыкальные сочинения и молитвы отцов Антиохийской церкви;

4. церковная музыкальная традиция Византийской империи (каванин иунанийа - буквально греческие законы), являвшейся для Сирийской церкви значимым авторитетом [1].

Музыкальная культура сирийской православной церкви преодолела долгий путь в своем развитии, вбирая в себя особенности каждого конкретного исторического периода и оказывая значительное влияние на дальнейшее формирование музыкального наследия Сирии. К сожалению, следует констатировать, что из-за устоявшейся устной передачи и отсутствия навыка нотного письма, многое в этой традиции не сохранилось до наших дней.

В результате исследования установлено, что корни религиозной сирийской музыки скрыты в дохристианской эпохе, в языческих церемониях древних храмов
Месопотамии и Сирии. Свидетельством продолжения этого древнего музыкального наследия в христианскую эпоху и его проникновения в сирийскую церковь является так называемый Икадис, восьмиладовая музыкальная традиция, существовавшая на территории Ближнего Востока вплоть до арабского завоевания.

Мы также пришли к выводу, что данная традиция не исчезла в VII веке, но была использована арабами при создании их собственных макамов. Отличительными чертами сирийской церковной музыкальной традиции являются:

1. простота формы исполнения композиций;

2. передача музыкального наследия осуществлялась устно и опиралась на фольклорную традицию, близкую и понятную широким слоям населения - богослужение проводилось на простом и понятном для каждого верующего языке;

3. общей стилистике исполнения были присущи спокойствие и одухотворенность. Основное внимание акцентировалось на эмоционально-чувственном восприятии;

4. наличие расстояние между четвертями, что роднит её с музыкальной четвертичной традицией Ближнего Востока (арабско-турецкой и персидской);

5. наличие в музыкальных композициях собственного уникального ритма;

6. наличие в некоторых мелодиях элементов поэтических параллелей.

Нури Искандар один их самых влиятельных композиторов XX века, чье музыкальное наследие значительно обогатило современную сирийскую музыкальную культуру и повлияло на неё. Есть все основания утверждать, что в том числе благодаря творчеству этого композитора музыкальная традиция сирийского православия значительно повлияла на сирийскую современную музыку.

Тема влияния сирийской церковной музыкальной традиции на светскую музыку может быть интересна культурологам как в России, так и в других странах. Изучение взаимного обогащения различных музыкальных культур, их генезиса и развития представляется важной темой для исследователей XXI века по всему миру.

\section{ЛИТЕРАТУРА}

1. Аль-Бюльбюль Наги Сабах Фахри [Электронный ресурс]. - Режим доступа: https://www.youtube.com/watch?v=zaZVDj88G2Y\&ab_channel=latito007 (дата обращения - 10 апреля 2021 года)

2. Барсом. И.А. Рассеянный жемчуг. История сирийской литературы и наук,1920. - 611 с.

3. Дауд Ахмед. История Сирии Древняя цивилизация - т. 2. Дамаск: Дар-Ал-шарк Полиграфия и издательская деятельность, 2004. - 703 с.

4. Колокола Востока - Нури Искандар - композитор [Электронный ресурс]. - Режим доступа: https://www.youtube.com/watch?v=kD_hs1G6FZk (дата 06- 
ращения - 10 апреля 2021 года)

5. Новый Завет [Электронный ресурс]. - Режим доступа: http://www.patriarchia.ru/bible/jn/ (дата обращения - 12 апреля 2021 года)

6. Роберсон Р. Восточные христианские церкви. СПб.: 1999. - 45 с.

7. Самир Абду. Сирия православная старая и современная. - Амман: Дар Аль Шурук, 2010. - 117 с.

8. Самим Эль Шериф. Музыка в Сирии - Музыканты и история - Дар Аль-Асад, 2011 - 800 с.

9. تر عو ديلوخ حانونو /بابك ايه الحنو. [Электронный ресурс]. - Режим доступа: https://www.youtube.com/watch?v=AS_LxR700Rs\&ab_channel=Aws.j (дата обращения -10 апреля 2021 года)

() Максуд Марлен (marilyn.maksoud@gmail.com).

Журнал «Современная наука: актуальные проблемы теории и практики»

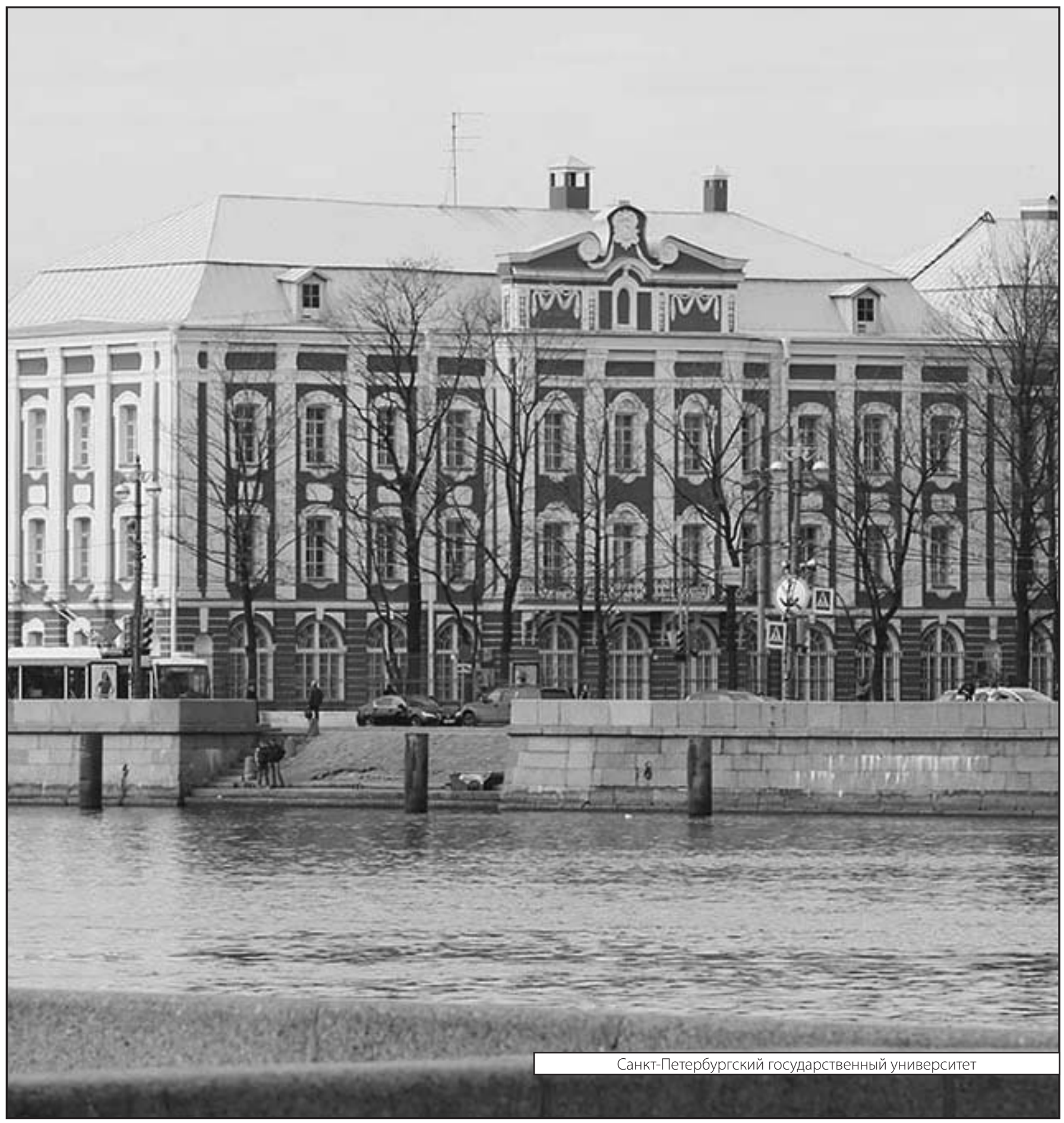

